\title{
STUDENTS' DISTRIBUTIVE REASONING WITH FRACTIONS AND UNKNOWNS
}

\author{
Amy Hackenberg \\ Indiana University \\ ahackenb@indiana.edu
}

\author{
Mi Yeon Lee \\ Indiana University \\ miyelee@indiana.edu
}

To understand relationships between students' quantitative reasoning with fractions and their algebraic reasoning, a clinical interview study was conducted with 18 middle and high school students. The study targeted a balanced mix of students with 3 different multiplicative concepts, which are based on how students coordinate composite units (units of units). Students participated in two 45-minute semi-structured interviews and completed a written fractions assessment. This paper reports on how students with the second and third multiplicative concepts demonstrated the use of a distributive operation in fraction and algebraic problem solving.

Fractional knowledge is regarded as important for algebraic reasoning (Kilpatrick \& Izsak, 2008; National Mathematics Advisory Panel [NMAP], 2008; Wu, 2001), in part because such knowledge is a basis for typical algebra topics such as ratios and slopes of lines. More generally, fractional knowledge is important for learning algebra because it helps students advance their multiplicative reasoning (cf. Thompson \& Saldanha, 2003). For example, generating strategies for multiplying fractions can help students develop a distributive operation (Hackenberg \& Tillema, 2009): to determine $1 / 5$ of $3 / 4$ of a yard a student can take $1 / 5$ of each of the three onefourths of the yard. So, $1 / 5$ of $3 / 4$ is $1 / 5$ of $(1 / 4+1 / 4+1 / 4)$. Thinking of $1 / 5$ of $3 / 4$ in this way might be considered algebraic because it highlights how the distributive property emerges from reasoning and is powerful for solving problems. However, little research has focused on how students' ways of operating with fractions may influence their algebraic reasoning (Lamon, 2007).

The purpose of this paper is to examine the distributive reasoning with fractions and unknowns of 18 middle and high school students who participated in a clinical interview study. The study was designed to investigate relationships between students' quantitative reasoning with fractions and their algebraic reasoning in the area of equation solving. In this paper we assess whether students with different multiplicative concepts demonstrated the use of a distributive operation in their quantitative reasoning with fractions and their algebraic reasoning.

The research questions addressed in this paper are:

1) Do middle and high school students show evidence of a distributive operation in solving problems that involve sharing multiple units fairly? If so, how do they reason distributively?

2) Do middle and high school students show evidence of a distributive operation in solving problems involving unknowns and fractions? If so, how do they reason distributively?

3) What differences are there in the distributive reasoning of students with different whole number multiplicative concepts?

\section{Quantitative Reasoning}

\section{A Quantitative and Operational Approach}

Following Thompson and colleagues (1993; Smith \& Thompson, 2008), we conceive of quantity and quantitative reasoning as a basis for helping students build fractional knowledge and algebraic reasoning. A quantity is a property of one's concept of an object, and to conceive of a quantity requires a person to conceive of a measurement unit, of the property as subdivided

Wiest, L. R., \& Lamberg, T.(Eds.).(2011). Proceedings of the 33rd Annual Meeting of the North American Chapter of the International Group for the Psychology of Mathematics Education. Reno, NV: University of Nevada, Reno. 
into some number of these measurement units, and of a way to enumerate the number of these units to find a value of the quantity (cf. Thompson, 1993).

Approaching fractions as quantities means that we pose problems to students in which fractions are measureable extents, or lengths; these lengths may represent other quantities as well (e.g., weight). Approaching algebraic reasoning from a quantitative perspective means that unknowns are quantities for which a value is not known, but for which a value could be determined. So unknowns are potential values of quantities. In working with students we routinely ask them to make drawings of quantitative relationships, and we aim for students' fraction and algebraic notation to reflect the quantitative reasoning in which students engage. Operations and Schemes

Our work is also based on conceiving of mathematical thinking in terms of people's mental actions, or operations (von Glasersfeld, 1995). Operations that are critical for fractional knowledge include partitioning, or marking a part into some number of equal pieces, as well as iterating, or repeatedly instantiating a part to make a larger fraction. The operation under investigation in this paper is a distributive operation. At the start of the study we characterized this operation as applying a process to a composite unit (a unit of units) by applying that process to some segmentation of the units that make up the composite unit. For example, to take $2 / 5$ of 3 pounds a student could take $2 / 5$ of each of the unit pounds that make up the 3 pounds. Our findings address whether this conceptualization of a distributive operation is sufficient.

Operations are the components of schemes, goal-directed ways of operating that consist of an assimilated situation, activity, and a result (von Glasersfeld, 1995). For example, if a student has constructed a partitive fraction scheme, then a situation of the scheme is a request to make a new length that is $2 / 5$ of a foot. The activity of the scheme involves partitioning the foot into five equal parts, disembedding one of those parts, and iterating the part twice. The student then assesses this result in relation to what she expected. We take students' reasoning to be the functioning of their schemes and operations in on-going interaction in their experiential worlds. Multiplicative Concepts

For us, a concept is the result of a scheme that people have interiorized-i.e., reprocessed so that the result is available prior to operating. We use students' whole number multiplicative concepts as a tool for understanding differences in how students build fractional knowledge (e.g., Hackenberg, 2010). These multiplicative concepts are based the number of levels of units a student has interiorized; to progress from one concept to the next requires a major reorganization of operations. Although this study included students with three different multiplicative concepts, this paper reports only on students with the second and third multiplicative concepts, as derived from prior research (Hackenberg \& Tillema, 2009; Steffe, 1994), because students with the first multiplicative concept did not show evidence of a distributive operation.

Students with the second multiplicative concept (MC2 students) have interiorized two levels of units. These students have the potential to treat a length as a unit containing some number of equal units, and they can do so prior to operating in a situation. For example, these students can treat a length that represents one foot as a unit containing five units - a unit of units structurewithout having to actually make the partitions. These students can also make three levels of units in activity. For example, they can insert three parts into each of the five parts in the $5 / 5$-foot segment and determine that they have made 15 parts in all. However, once they do so, the 15/15foot segment is not likely to retain its structure as unit of five units each containing three units (Hackenberg, 2010; Hackenberg \& Tillema, 2009).

Students with the third multiplicative concept (MC3 students) have interiorized three levels

Wiest, L. R., \& Lamberg, T. (Eds.). (2011). Proceedings of the 33rd Annual Meeting of the North American Chapter of the International Group for the Psychology of Mathematics Education. Reno, NV: University of Nevada, Reno. 
of units. Prior to operating, these students can treat lengths as a unit containing some number of units, each of which contains some number of units - a unit of units of units structure. So, in the example above, MC3 students can do what MC2 students do, but they can also retain views of the 15/15-foot segment as a unit of 5 units each containing 3 units, and they can switch to viewing the segment as a unit of 3 units each containing 5 units. Being able to flexibly switch between such unit structures can be useful for constructing a variety of fraction schemes (e.g., Hackenberg, 2010; Steffe \& Olive, 2010).

\section{Methods}

A clinical interview study was chosen as appropriate methodology to explore the research questions because a strength of clinical interviewing is "the ability to collect and analyze data on mental processes at the level of a subject's authentic ideas and meanings, and to expose hidden structures and processes in the subject's thinking that could not be detected by less open-ended techniques" (Clement, 2000, p. 547). Interview studies are a tool for generating scientific knowledge because dynamic, on-going discussion is a basis for formulating explanatory models (Clement, 2000; Steffe \& Thompson, 2000) for experienced phenomenon.

Seven seventh grade students, 10 eighth grade students, and one tenth grade student participated in the study. Participant selection occurred via classroom observations, consultation with students' teachers, and one-on-one, task-based selection interviews to assess students' multiplicative concepts. Six students with each multiplicative concept were invited to participate. Four of the MC2 students were enrolled in an $8^{\text {th }}$ grade pre-algebra class; one was taking an advanced $7^{\text {th }}$ grade mathematics class; and one was taking a $7^{\text {th }}$ grade mathematics class for struggling students. Four of the MC3 students were enrolled in an algebra class, and two were taking an advanced $7^{\text {th }}$ grade mathematics class.

Students participated in two 45-minute semi-structured interviews, a fractions interview and an algebra interview. All students completed the fractions interview prior to the algebra interview, but the time between interviews varied from about 3 weeks to 4 months. The interview protocols were refined in a prior pilot study (Hackenberg, 2009), and quantitative situations were used as a basis for all problems. The protocols were designed so that the reasoning involved in the fractions interview was a foundation for solving problems in the algebra interview. For example, in the fractions interview students were posed this problem:

F2. Fair Sharing of Multiple Identical Bars Problem: Here are five candy bars (congruent rectangles). Can you show how to share them fairly among seven people, and determine the fair share for one person? Draw the amount one person gets.

In the algebra interview, students were posed a similar problem but with each bar assigned a weight of $h$ ounces:

A1. Weight of Multiple Identical Bars Problem: Here are five identical candy bars (congruent rectangles). Each candy bar weighs some number of ounces. Let's say that $h=$ the weight of one bar. How much does $1 / 7$ of all the candy weigh? Write an expression for this result.

In working on A1, students were also encouraged to draw a picture to demonstrate how they saw their expression. In addition to the two interviews, students completed a written fractions assessment (Norton \& Wilkins, 2009) to triangulate claims about their fractional knowledge.

Each interview was video-recorded with two cameras, one focused on the interaction between the researcher and student, and one focused on the student's written work. The videos were mixed into one file for analysis, which occurred in two overlapping phases. First, the researchers viewed video files and took detailed notes (Cobb \& Gravemeijer, 2008). The aim of

Wiest, L. R., \& Lamberg, T. (Eds.). (2011). Proceedings of the 33rd Annual Meeting of the North American Chapter of the International Group for the Psychology of Mathematics Education. Reno, NV: University of Nevada, Reno. 
this phase was to formulate a model of each student's fraction schemes and equation solving activity, to the extent possible over two interactions. To develop these models the researchers built on constructs from prior models (e.g., Hackenberg, 2010; Steffe \& Olive, 2010; Tzur, 2004). These models provided the basis for responding to the first two research questions.

In the second phase of analysis, the researchers looked across the students to articulate differences in how students with different multiplicative concepts solved the problems in each interview. This phase included assessing differences in students' distributive reasoning with knowns and unknowns and writing syntheses of differences for students with each multiplicative concept. This phase allowed the researchers to address the third research question in this paper.

\section{Analysis and Findings}

Four of the MC2 students demonstrated some evidence of a distributive operation in the fractions interview, while only one of the MC3 students did so. In this section we present data and analysis to support this finding, which was surprising, since prior to the study we conjectured that a distributive operation required the third multiplicative concept. Then we examine the students' work on the algebra interview to help illuminate the finding.

\section{Distributive Reasoning in the Fractions Interview}

MC2 students. Of the four MC2 students who demonstrated evidence of a distributive operation in the fractions interview, two demonstrated it immediately upon sharing three identical candy bars fairly among five people, which we'll call problem F1, as well as in working on F2. The other two students showed some evidence of a distributive operation over time in working on F1 and F2. We present an example of each of these two types of evidence.

In work on F1, Lisa immediately divided each of the three bars into five equal parts and said that each person would get one-fifth from each bar. She seemed certain, and she called the fair share that she drew three-fifths. When asked whether the share was $3 / 5$ of all the candy or $3 / 5$ of one bar, she said it was $3 / 5$ of all the candy. Upon further questioning, she said $3 / 5$ referred to "kind of both" (all the candy and one bar), because the share was $3 / 5$ from one bar and 1/5 from each of three bars. Twenty seconds later, when asked if each person got 3/5 of all the candy, she said no. She noted that there were five people so one share was one-fifth of all the candy. She solved F2, directly following F1, in the same say. She said, "Each person will get one-seventh of all the candy, because there are seven people. And they will get one-seventh of each [bar]." She said each person would get five-sevenths.

This data excerpt demonstrates that Lisa has constructed a distributive operation of some kind, in that to take find $1 / 5$ or $1 / 7$ of multiple identical units she took $1 / 5$ or $1 / 7$ of each of those units. However, for some time in working on F1 she named the fair share $3 / 5$ of all the candy. Our interpretation is that to determine a share, Lisa made a unit of units of units in activity: All of the candy was a unit of three units, and she partitioned each of those units into five units. Once she determined a share, she continued to view all the candy as the referent for the result, even though she also she viewed each bar as a unit of five units. Lisa said that one person's share was $1 / 5$ of all the candy only after she thought again about five people sharing all of the bars; then she viewed the share as $1 / 5$, consistent with viewing all of the bars as a length partitioned into five equal parts (a unit of units). So, she appeared to view the results of her activity as different two-levels-of-units views, but not as a three-levels-of-units view. A second MC2 student operated similarly to Lisa.

In contrast with Lisa, Sheila was one of the two MC2 students who seemed to develop a distributive operation in the process of the interview. Her fractions interview was one of the first

Wiest, L. R., \& Lamberg, T. (Eds.). (2011). Proceedings of the 33rd Annual Meeting of the North American Chapter of the International Group for the Psychology of Mathematics Education. Reno, NV: University of Nevada, Reno. 
in the study, and the interviewer inadvertently posed F1 with four people instead of five. Sheila solved this version of F1 by partitioning each of the first two bars in half, and then she partitioned the third bar into fourths. She said that each person would get "one-half plus onefourth." In working on F2 Sheila first partitioned each of the five bars into fourths, and she numbered the fourths from 1 to 7 sequentially, as if trying to determine whether the there would be an equal number of parts for each of seven people. She then tried again but partitioned each bar into fifths, again numbering sequentially. On her third try, she partitioned each bar into sevenths, numbered them sequentially, and said that each person would get "five-sevenths." That is, each person would get all the pieces with the same number on them (person 1 gets all the 1's).

So, Sheila's work on F1 and F2 is not evidence of a distributive operation. However, in the course of the interview, she introduced the idea of numbering the pieces to try to pull out an equal amount for each of the seven people. This idea seems to be a possible root for a distributive operation, in that through it Sheila determined that she could make fair shares by taking one part out of seven from each of the five bars.

MC3 students. In contrast, the only MC3 student to demonstrate a distributive operation in working on F1 and F2 was Liam. In working on F1, Liam immediately said that you could divide each bar into five parts, but "that would be kind of cumbersome." So, he drew his three bars stacked vertically and then partitioned them vertically, all at once, into fifths. He then drew out one column (consisting of three parts) as the share for one person. He called one share 3/15 and then $1 / 5$ of all the candy. When asked for the size of the share in relation to one bar, he paused and appeared to do some calculation. He justified his answer of $3 / 5$ of one bar by saying that one column was the same as three parts horizontally, which was $3 / 5$ of a bar. He solved F2 similarly, although he determined the size of one share in relation to one bar, $5 / 7$, first. To determine the fraction of all the candy, he calculated $5 / 7 \times 1 / 5$ and found $5 / 35$, or $1 / 7$. He said he had multiplied because one share was $5 / 7$ of a candy bar, and a candy bar was $1 / 5$ of the total.

Although his process is somewhat different from Lisa's, it still implies the construction of a distributive operation because one column consists of one part from each bar. However, Liam may not have been aware of this pattern in his thinking. For example, when asked in F2 whether his result of his calculation to determine the fraction of all the candy, 1/7, made sense, he pointed out that the seven shares in the five bars could be seen in five horizontal rows $(5 / 7$ of each bar) and then two more columns, each containing five parts. He did not point to each column.

The other MC3 students did not reason distributively in the fractions interview, although some of them made sophisticated solutions. For example, Suzanne tried out a fractional amount of each bar as the share for one person and then looked to see what was leftover. In F2 she first tried a share of $2 / 3$ of a bar, and knew she could give that to 5 people, because there were 5 bars. She then saw that she had five-thirds leftover, which left an extra one-third after two more people each got $2 / 3$ of a bar. So, then she tried a share of $3 / 4$, followed by $4 / 5$, followed by $5 / 7$. Distributive Reasoning in the Algebra Interview

In working on A1, five of the MC2 students did not demonstrate distributive reasoning with unknowns. Only Sheila's work on this problem indicates that she was continuing to develop the distributive reasoning that had emerged in the fractions interview. First we present Lisa's response to A1, followed by an analysis of Sheila's response. Then we discuss the ways of operating of the MC3 students on A1, again highlighting the work of Liam and Suzanne.

MC2 students. After being posed A1, Lisa again demonstrated a possible distributive operation by partitioning each of the five bars into seven equal parts and saying that she would take "one from each." However, when asked to draw out that amount, she believed that it would

Wiest, L. R., \& Lamberg, T. (Eds.). (2011). Proceedings of the 33rd Annual Meeting of the North American Chapter of the International Group for the Psychology of Mathematics Education. Reno, NV: University of Nevada, Reno. 
be a whole bar. After she had insisted on this result for over two minutes, the interviewer counted the pieces when taking one from each bar, and Lisa said that the result would only make $5 / 7$ of a bar. When asked how she knew that result was one-seventh of all of the candy, she repeated her process (taking 1/7 of each, and that will be 5/7). The interviewer pressed for another fraction name for the result in relation to all of the candy, and she said 5/7. Then the interviewer asked whether the result would be more or less than the weight of one bar, $h$. She said less, because it was less than one bar. When asked for an expression, she said she did not know how to write it, and she wrote down " $\mathrm{H}<$ ".

This piece of data sheds more light on the nature of Lisa's distributive operation. Her initial response to A1 was similar to her initial response to F2, allowing us to corroborate that Lisa has constructed a mental action - accompanied by material manifestations - for taking 1/7 of all of the bars by taking 1/7 from each bar. However, in working on A1 she did not appear to realize for some time that that her action would of necessity produce five pieces; she thought it would be a whole bar. So she appeared to lack awareness of the result of her operation. In addition, once she had made the result, she did not appear to have any way outside of her initial action to justify that the share she produced was one-seventh of all the candy. In fact, in A1 it's not clear that Lisa viewed the result as one-seventh of all the candy. It was almost as if the initial problem of finding one-seventh of all of the bars became lost to her once she arrived at her result, fivesevenths. We account for this as we did with her work on F2, by appealing to her multiplicative concept. Lisa made three levels of units in activity by partitioning each of the five bars into seven. However, once she did that, she did not appear to retain the structure of the bars as a unit of five units each containing seven, and we have no evidence that she switched to a view of the entire collection as a unit of seven units each containing five.

In working on A1, Sheila operated similarly to Lisa in that she immediately divided each bar into seven equal parts and colored the first part of each bar. When asked for the weight of that, she said "There are five, so five-sevenths of one candy bar." The interviewer asked her to write an expression using $h$ to show the weight of this amount. Sheila wrote 5/7h. In explanation, she said that she had multiplied five-sevenths and $h$.

Because Sheila had worked so swiftly on A1, the interviewer posed A2:

A2. Weight of Three Different Bars Problem: There are three candy bars on the table, each of different weight (three non-congruent rectangles). The first bar weighs $a$ ounces; the second bar weighs $b$ ounces; and the third bar weighs $c$ ounces. How much does three-fifths of all the candy weigh? Write an expression to show your result.

Sheila partitioned each of the three bars into five equal parts, colored the first piece of each bar, and wrote " $3 / 5 b$ ". Then she tried to fit the bars together in some way. The interviewer clarified that the bars had no particular relationship to each other and decided to pursue finding just onefifth of the weight. Sheila then wrote that the weight was " $3 / 15 b$." When asked what $1 / 5$ of the first bar weighed, Sheila answered " $1 / 5 a$." The interviewer asked similar questions for the other two bars, and Sheila answered similarly. When asked about the weight of all three parts together, Sheila pointed to her expression " $3 / 5 b$." The interviewer then asked her to write an expression that included $a, b$, and $c$, using her ideas about the weights of one-fifth of each bar. Sheila wrote " $3 / 5 \cdot c \cdot b \cdot a$ " and said, "multiplying $3 / 5$ by the third bar, by the second bar, and by the first bar."

Sheila's work on A2 helps illuminate the nature of her distributive operation that appeared so fluidly in her work on A1. Like Lisa, Sheila had constructed a mental action that we refer to as distributive. Unfortunately, on A1 the interviewer did not press Sheila for the fraction name of the result in relation to all the candy, so we cannot draw conclusions about whether she could

Wiest, L. R., \& Lamberg, T. (Eds.). (2011). Proceedings of the 33rd Annual Meeting of the North American Chapter of the International Group for the Psychology of Mathematics Education. Reno, NV: University of Nevada, Reno. 
justify that $5 / 7$ of the weight of one bar was $1 / 7$ of the weight of all of the bars. However, in working on A2, like Lisa, Sheila did not appear to be aware of the result of her activity. Furthermore, in A2 Sheila's work does not indicate that she viewed 1/5 of the weight of all the candy either as the sum of $1 / 5$ of the weight of each bar, or as $1 / 5$ of the sum of the three weights. We account for this by appealing to Sheila's multiplicative concept: Once she had partitioned each bar in A2, the problem likely became a unit of 15 units, and so a response like " $3 / 15 b$ " was a reasonable response for the weight of $1 / 5$ of those units.

MC3 students. In contrast with the MC2 students, four MC3 students demonstrated distributive reasoning with unknowns in the algebra interview. Liam's work on A1 showed a distributive operation more clearly than his work on F2. He wrote the result as $(5 h) / 7$ and $5 h$ • $1 / 7$. When asked to show that in the picture, he partitioned each bar into sevenths and said to take one from each, gesturing to the first part from each bar. He drew out this amount, and when asked how much that was of $h$, he said 5/7. However, in his work on A2, Liam only arrived at ( $a$ $+b+c) \cdot 3 / 5$ to express $3 / 5$ of the weight of three bars of different weight. Despite several opportunities, he did not ever articulate $3 / 5$ of the weight of the bars as $3 / 5 a+3 / 5 b+3 / 5 c$.

In her work on A1 and A2, Suzanne seemed to develop her distributive reasoning even more than Liam. On A1 she first wrote $5 h \bullet 1 / 7$ as her expression. To make her drawing, she partitioned each bar into seven equal parts and marked the last part of each bar. She said you could put all of those parts together to make $1 / 7$ of all the candy. She drew out that amount and wrote $5 / 7 h$ for its weight. When asked whether the two expressions were the same, she noted that multiplying 5 times $1 / 7$ produced 5/7. On A2, Suzanne wrote two expressions for the weight of the three different bars and explained that the first one, $3 / 5(a+b+c)$, meant that you added all the bars together and took $3 / 5$ of it. The second one $(3 / 5 a+3 / 5 b+3 / 5 c)$ meant that you took $1 / 5$ of each weight and then added. Based on this work, we attribute a distributive operation to Suzanne in which she had developed awareness of the result of the mental action.

\section{Discussion and Conclusions}

In this section we summarize our responses to our three research questions. First, MC2 students can develop a distributive operation in which they take a fractional amount of each unit to make a fractional amount of multiple units, and they may believe that this action accomplishes this goal. However, these students do not necessarily distinguish the fractional meaning of the result in relation to the unit versus the multiple units. In addition, they do not necessarily have a way to justify that their method works. We attribute this to their interiorization of two, but not three, levels of units, as we have discussed above. The main issue is that after partitioning multiple units, the multiple bars becomes a unit of units for these students, rather than a threelevels-of-units structure. This finding causes us to refine our definition of a distributive operation to include being able to distinguish different referent units in the results of operating.

Second, our study supports the conclusion that MC3 students have constructed the means for constructing a distributive operation. Our analysis of what is required to develop awareness of the result of the action, and a way to justify that the action produces a correct result, relies on being able to switch three-levels-of-units structures - a hallmark of the third multiplicative concept. However, third, our study also shows that even though MC3 students have this kind of power at their disposal, they will not necessarily use it to construct a distributive operation unless given opportunities to do so, i.e., unless instruction and tasks are organized favorably for this.

So, one implication of this study for teaching is to work on sharing multiple units in such a way that students construct a distributive operation that they can further develop in algebraic

Wiest, L. R., \& Lamberg, T. (Eds.). (2011). Proceedings of the 33rd Annual Meeting of the North American Chapter of the International Group for the Psychology of Mathematics Education. Reno, NV: University of Nevada, Reno. 
contexts. This can make it possible for discussions of whether $5 h * 1 / 7$ is the same as $(5 / 7) h$ to have quantitative, not just numerical, meaning - an issue that appears to be within the cognitive powers of MC3 students. Although such work may be challenging for MC2 students, an open question is whether it may be influential in helping them advance their multiplicative concepts.

\section{References}

Cobb, P., \& Gravemeijer, K. (2008). Experimenting to support and understand learning processes. In A. E. Kelly, R. A. Lesh \& J. Y. Baek (Eds.), Handbook of design research methods in education: Innovations in science, technology, engineering, and mathematics learning and teaching (pp. 68-95). New York: Routledge.

Clement, J. (2000). Analysis of clinical interviews: Foundations and model viability. In R. Lesh \& A. E. Kelly (Eds.), Handbook of research design in mathematics and science education (pp. 547-589). Hillsdale, NJ: Erlbaum.

Hackenberg, A. J. (2009). Relationships between students' fraction knowledge and equation solving. Paper presentation at the Research Pre-session of the annual conference of the National Council of Teachers of Mathematics (NCTM), Washington, D.C.

Hackenberg, A. J. (2010). Students' reasoning with reversible multiplicative relationships. Cognition and Instruction, 28(4), 1-50.

Hackenberg, A. J., \& Tillema, E. S. (2009). Students' whole number multiplicative concepts: A critical constructive resource for fraction composition schemes. Journal of Mathematical Behavior, 28, 1-18.

Kilpatrick, J., \& Izsak, A. (2008). A history of algebra in the school curriculum. In C. Greenes (Ed.), Algebra and algebraic thinking in school mathematics: 2008 NCTM yearbook (pp. 318). Reston, VA: NCTM.

Lamon, S. J. (2007). Rational numbers and proportional reasoning. In F. K. J. Lester (Ed.), Second Handbook of Research on Mathematics Teaching and Learning (pp. 629-667). Charlotte, NC: Information Age.

National Mathematics Advisory Panel (NMAP). (2008). Report of the task group on conceptual skills and knowledge. Washington, DC: U.S. Department of Education.

Norton, A., \& Wilkins, J. L. M. (2009). A quantitative analysis of children's splitting operations and fraction schemes. Journal of Mathematical Behavior, 28, 150-161.

Smith, J. P., \& Thompson, P. W. (2008). Quantitative reasoning and the development of algebraic reasoning. In J. J. Kaput, D. W. Carraher \& M. L. Blanton (Eds.), Algebra in the early grades (pp. 95-132). New York: Lawrence Erlbaum.

Steffe, L. P. (1994). Children's multiplying schemes. In G. Harel \& J. Confrey (Eds.), The development of multiplicative reasoning in the learning of mathematics (pp. 3-39). Albany, NY: State University of New York Press.

Steffe, L. P., \& Olive, J. (2010). Children's fractional knowledge. New York: Springer.

Steffe, L. P., \& Thompson, P. W. (2000). Teaching experiment methodology: Underlying principles and essential elements. In R. Lesh \& A. E. Kelly (Eds.), Handbook of research design in mathematics and science education (pp. 267-306). Hillsdale, NJ: Erlbaum.

Thompson, P. W. (1993). Quantitative reasoning, complexity, and additive structures. Educational Studies in Mathematics, 25, 165-208.

Thompson, P. W., \& Saldanha, L. A. (2003). Fractions and multiplicative reasoning. In J. Kilpatrick, W. G. Martin \& D. Schifter (Eds.), Research companion to the principles and standards for school mathematics (pp. 95-113). Reston, VA: NCTM.

Wiest, L. R., \& Lamberg, T.(Eds.).(2011). Proceedings of the 33rd Annual Meeting of the North American Chapter of the International Group for the Psychology of Mathematics Education. Reno, NV: University of Nevada, Reno. 
Tzur, R. (2004). Teacher and students' joint production of a reversible fraction conception. Journal of Mathematical Behavior, 23, 93-114.

von Glasersfeld, E. (1995). Radical constructivism: A way of knowing and learning (Vol. 6). London: Falmer.

Wu, H. H. (2001). How to prepare students for algebra. American Educator, 25(2), 10-17.

Wiest, L. R., \& Lamberg, T. (Eds.). (2011). Proceedings of the 33rd Annual Meeting of the North American Chapter of the International Group for the Psychology of Mathematics Education. Reno, NV: University of Nevada, Reno.

Articles published in the Proceedings are copyrighted by the authors. 